\title{
Erratum to: Predictors of the Development of Surgical Complications among Hematopoietic Stem Cell Transplantation Recipients
}

\author{
Iyad Anabtawi • Fawzi Abdelrahman • \\ Ahamd Alomari · Murad Ba'ba' • Mahmoud Al Masri
}

Published online: 19 June 2012

(C) Société Internationale de Chirurgie 2012

Erratum to: World J Surg (2012) 36:1003-1010

DOI 10.1007/s00268-012-1517-0

In the original article there are errors in Table 6 column headings. Following is the corrected table:

Table 6 Immunity status vs. complications

\begin{tabular}{llcccc}
\hline $\begin{array}{l}\text { Time of } \\
\text { complication }\end{array}$ & Complications & $\begin{array}{l}\text { Total } \\
\text { complications }\end{array}$ & $\begin{array}{l}\text { Immune } \\
\text { competent }(\%)\end{array}$ & $\begin{array}{l}\text { Immune } \\
\text { compromised }(\%)\end{array}$ & $P$ value \\
\hline Before & Abdominal & 62 & $15(42.9)$ & $47(57.3)$ & 0.15 \\
& Urinary & 10 & $2(5.6)$ & $8(9.8)$ & 0.72 \\
& CNS & 1 & & $1(1.2)$ & 0.51 \\
& Perianal & 14 & $5(13.9)$ & $9(11)$ & 0.65 \\
& Musculoskeletal & 4 & $3(8.3)$ & $1(1.2)$ & 0.08 \\
& ENT & 17 & $7(17.9)$ & $10(12.7)$ & 0.44 \\
Total & Catheter & 48 & $16(44.4)$ & $30(37.5)$ & 0.48 \\
& & 156 & & & \\
& Abdominal & 60 & $57(61.3)$ & $3(33.3)$ & 0.1 \\
& Urinary & 7 & $7(7.7)$ & & 0.39 \\
& CNS & 3 & $1(1.1)$ & $2(20.0)$ & 0.03 \\
& Perianal & 7 & $6(6.6)$ & $1(11.1)$ & 0.49 \\
& Musculoskeletal & 2 & $2(2.2)$ & & 0.65 \\
& ENT & 14 & $12(13.2)$ & $2(22.2)$ & 0.61 \\
& Catheter & 30 & $23(26.4)$ & $7(53.8)$ & 0.04 \\
\hline
\end{tabular}

The online version of the original article can be found under doi:10.1007/s00268-012-1517-0.

I. Anabtawi · A. Alomari · M. Ba'ba' · M. Al Masri ( $₫)$

Department of Surgery, King Hussein Cancer Center, Queen

Rania Street, P.O. Box 1269, Al-Jubeiha, Amman 11941, Jordan

e-mail: malmasri@khcc.jo

F. Abdelrahman

Department of Bone Marrow and Stem Cell Transplantation

Program, King Hussein Cancer Center, Amman, Jordan 